appropriate to make comparison and the main message that these systems can be successful but do require supply through a fully trained team providing ongoing support mirrors the experience of those who have produced satisfactory research results elsewhere.

John Stallard B Tech, C Eng, FI Mech E, FBES, FBIST(Hon) Technical Director Orthotic Research \& Locomotor Assessment Unit Robert Jones \& Agnes Hunt Orthopaedic Hospital Oswestry SY10 7AG, UK

1 Banta JV, Bell KJ, Muik EA, Fezio. ParaWalker: Energy cost of walking. Eur. J. Pediatric Surg. 1991; 1: Suppl 1: 7-10.

2 Bowker P, Messenger N, Ogilvie C, Rowley D. The energetics of paraplegia walking. Journal of Biomedical Engineering 1992; 14: 344-350.

3 Lotta S, et al. Paraplegia 1994; 32: 608-615.

4 Moore P, Stallard J. A Clinical review of adult paraplegic patients with complete lesions using the ORLAU ParaWalker. Paraplegia 1991; 29: 191-196.

5 Stallard J, Major RE. The use of the ORLAU ParaWalker by adult myelomeningocoele patients: a seven year retrospective study. To be presented at 39th Annual Scientific Meeting of the Society for Research into Hydrocephalus and Spina Bifida, Bristol 5-8 July 1995.

6 Whittle MW, Cochrane GM. A comparative evaluation of the hip guidance orthosis (HGO) and the reciprocating gait orthosis (RGO). Health Equipment Information, London: National Health Service Procurement Directorate, 1989, 192.

\section{Reply from Dr L Tesio MD}

We are grateful to Mr Stallard for his keen analysis of our paper evidencing a contradiction between the text and one table. We confirm that our four HGO patients could only walk with a walker. This has been a typing mistake for which we apologise to the editor and to readers.

We appreciated very much his opinion that, despite this flaw, the paper is not devoid of an overall impact. Perhaps the main aim of our epidemiologic study was a claim for more attention to the outcome as seen from patient's perspective rather than from a biomechanical standpoint. $\mathrm{Mr}$ Stallard is an eminent scientist in the field of gait engineering and we fully appreciate his statement that 'perhaps the most important measure of success is patient compliance'.

Dr Luigi Tesio

Department of Research Functional Assessment and Quality Assurance in Rehabilitation Fondazione Clinica de Lavoro via Clefi 9, 20146 Milan, Italy 